\title{
HUMORISMO Y FILOSOFIA: "LOS 'POBRESITO' POBRES" $Y$ "LOS CUARTRO EMBAJADORES"
}

\section{José Sánchez-Boudy}

El cubano es un pueblo que ama al chiste. Se oye continuamente en la calle. Es más, los cubanismos, es decir la forma típica de hablar del cubano, están impregnados, casi siempre, de lo chistoso. $Y$ el chiste siempre conlleva lo mismo: mover a risa. 1 No es el pueblo de Cuba una colectividad dedicada a crear chistes negros, o chistes filosóficos, o chistes en los que la médula es puro acíbar. El Chiste filosófico y el chiste negro tendrán su floración en el llamado destierro cubano, es decir esa época que comienza con la llegada del comunismo a Cuba en 1959 y que aún hoy - 1981 - continúa.

Por otro lado el chiste siempre tuvo zonas definidas: el teatro vernáculo; las parejas folklóricas como la que formaron en los años de la República el dúo de "Acebal y Otero"; o "Garrido y Piñeiro"; el artículo - sobre todo de raíz política - en el que sobresalieron José Castor Vispo, José Vergara y Miguel de Marcos; el costumbrismo de Eladio Secades. La novela apenas lo tocó, con excepción de las obras de Miguel de Marcos.

La commoción revolucionaria de 1959 lleva, pues, el chiste a la novela y con nuevos derroteros.

Es interesante notar, ahora, que el humorismo en el exilio, debido a esa conmoción, nunca ha tenido como fin inmediato el hacer reir. $\mathrm{Ni}$ aún cuando el chiste parece que se orienta en ese sentido. Si se examinan, por ejemplo, mis novelas, Lilayando, ${ }^{2}$ y Lilayando pal tu, ${ }^{3}$ tomadas en conjunto, se verá qui mi interés fue dar un cuadro vivo de un estamento de la sociedad cubana que se haya fuera de Cuba. De dibujar la chusmería, el choteo y el relajo criollo. De hacer, más que humorismo, sociología.

En el caso de Álvaro de Villa, nombre de pluma de Rolando Álvarez de Villa sucede lo mismo. Fabrica chistes pero la 
intención no es tanto hacer reir como exponer ideas filosóficas, en particular, sobre la vida y sobre el mundo contemporáneo. Este es el sentido vital de su novela humorística, finalista del Premio Planeta de 1974, titulada, Los "pobresitos" pobres. 4

No es, entiéndase bien, que Álvaro de Villa quite al chiste el sabor risible o la capicidad de mover a risa. Su chiste sí determina el estado de euforia, que le es propio, en el oyente. Pero comparado con su parigual en la ficción, presenta, repito, una cosmovisión: un mundo filosófico o sociológico.

En otra dirección está Celedonio González. Las escenas chistosas que aparecen en su obra muestran un antihumor o si se quiere, un humor caústico. El se ha propuesto dejar ver como el chiste en el exilio no llega, muchas veces, a tal, porque está impregnado de amargura.

El vivir fuera de Cuba, el haber sido arrancado de raíz de su patria, ha dado a Álvaro de Villa un sentido filosófico de la existencia. Lo ha hecho indagar en ella. De ahí que su primera novela: El olor de la muerte que viene, publicada en España en 1968 trate problemas de la culpa y de las relaciones entre el ser humano y su Creador. De ahí que en: Los "pobresitos" pobres sea muy difícil encontrar un chiste que no este preñado de filosofia.5 Entre los desprovistos de ella se encuentran: "Yo era tan pobre que a los once años sólo pude cumplir cinco." "Como nunca tuvo ropa interior la tía le pintaba un botón en la barriga." "No conviene perder la cabeza, porque si no, uno no tiene donde ponerse las orejas ni el pelo" (50). "Debe haber cier:o canibalismo en el amor, porque todo amante murcura al oído del otro: Te comería! (61) "La Sra de Altiplano tenía no solo lentes de contacto, sino una preciosa dentadura blanca que se reía sola y una peluca hermosísma teñida de rubio, que era el triunfo de la industria moderna porque venía con caspa y todo," (71); "Yo conocí una mujer tan fea que la pintó Picasso y quedó igualita" (88); "- Es lindo, parece de estilo Renacimiento Español aunque debe ser de Renacimiento Escocés, porque por el costado dice: "Bacalao de Escocia" (101).

En el plano que tratamos - chistes no filosóficos -, algunas veces no se trata de aislados como estos que se han copiado sino de una conversación matizada por ellos:

"El Director de Personal movió la cabeza sin entender, y continuó preguntándole: 
- Nacío...?

- Naturalmente que nací, señor, aún los más pobres nacen. Ud. cree que me pusieron como si yo fuera un huevo?

- Le pregunto qué dónde nacío.

- En una cama.

- En que parte?: - respondió el hombre impaciente ya.

- Supongo que para la parte de los pies, que es lo acostumbrado, señor Jefe de Personal de la John and John, Companía Importadora, Exportadora, Empacadora, Envasadora, Incorporated, S.A.

- Me refiero al país!

- Ah, sí, soy del país - dijo Pedro dulcemente.

- Cuántos años tiene?

- Los transcurridos desde que nací a la fecha.

- Cuando nació?

- No recuerdo, señor, yo era muy pequeñito entonces.

- Vive...?

- Hasta ahora sí, eso creo, pero vivo mal.

- Dónde?

- En mi casa.

- Vive en las afueras? (41 y 42).

- No, en las adentro, porque afuera me mojo si llueve.

Fuera de este diálogo chistoso y de los chistes sueltos, fuera de ellos y algunos más diseminados en las doscientas sesenta y cuatro páginas de la novela el chiste o tiene un contenido filosófico o un contenido irónico debido al sedimento pesimista que en su el pensar filosófico del autor el exilio ha depositado.

El chiste irónico que encierra una filosofía pesimista, se presenta inmediatamente en la novela. En su comienzo, con uno sin ese ingrediente, parece que ella va a ser simplemente chistosa. No es así. La obra empieza con este chiste puro: "La noche tejida en sombras, sombras de la noche originaria, repetía en cada atardecer al alba de la Creación. Cada día la naturaleza hace bis." 6 Pero inmediatamente el chiste se convierte en irónico: "Las mañanas son como las novias, quizás por eso los hombres siempre se las quieren dormir." (11) "Ahi cerca de los perros, los gatos, los pájaros y la tierra seca vemos una casucha que parece una ancianita que murió de pie porque no tenía donce caerse muerta" (11); "Cuando los niños nacen les dan una nalgada; a Pedro le dieron un puñetazo en la nariz" (13). "Solamente cuando cumplió su primer añito le dieron una lata de leche evaporada. En el segundo cumpleaños le vinieron 
a prestar el abrelatas" (13); "Bien dicen, cuando dicen, que el dinero se va volando. Lo malo es que viene a pie" (28); "Claro que en los programas de televisión siempre gana el bueno menos en un programa que es el noticiero" (34); "El pobre sufria de lo que llaman halitosis porque suena más bonito, pero que es sólamente mal aliento, que suena peor pero huele igual" (43); "Nadie se hace rico trabajando pero si haciendo trabajar a los demás (57); "Mi amada, que sin yo saberlo era uera, me dijo con igual ardor: - Acepto tu generoso efrecimiento querido. Dame tu córnea izquierda. Por rara casualidad estaban en el jardín donde nos hallábamos un notario, dos testigos y una grabadora portátil. Tuve que darle mi córnea izquierda. Desde entonces el tuerto soy yo y ella ve con sus dos ojos: - Soy sincera. Con un ojo te veía como un hombre aceptable. Ahora que puede verte con dos confieso que no eres mi tipo." (57)

El chiste se mezcla con las ideas políticas del autor o de otro tipo, muchas veces, y deja de ser irónico para ser completamente filosófico, come éste que copio:

Llegue a concluir que el mundo no dice la verdad $Y$ esto ha llegado a las esferas mucho más seria que las frívolas zonas de la literatura de ficción Un señor muy serio, de barbas blancas, filósofo y economista, escribió un libro gordísimo llamado "El Capital," y según me han asegurado el señor barbudo, contrariamente a lo que supone el título de su obra, aboga porque se instaure en el mundo la más espantosa miseria... El Sr. Einstein, aseguró, que el tiempo y el espacio eran más o menos lo mismo. $\mathrm{Si}$ esto es así podríamos afirmar sin temor a equivocarnos que da igual tener cuarenta años que cuarenta leguas. $Y$ que quieren ustedes, yo me resisto a creer que las cosas sean así. Yo no puedo ni pensar siqueira que en vez de decir a un amigo: "Cuanto tiempo hace que no te veo!" le tenga que decir: "Cuantos kilómetros hace que no te veo." O que en vez de decir con voz trémula a la amada de mis sueños: "Te daré los mejores años de mi vida." decirle: "Te daré los mejores acres de mi existencia." (146)

La filosofía se Alvaro de Villa se revierte algunas veces en acres críticas contra los existencialistas, contra los poetas malos, etc., pero no olvida la índole chistosa de lo que escribe:

- Le gusta el existencialismo? 
Pedro, que era, si se quiere, un intelectual de solapas de libros, le respondió con discreción.

- Bueno, sí, pero me gusta más el pollo frito.

- Qué opina usted de la frase de Sartre: "el hombres es una pasión inútil"?

- Que sí. Pero también creo, con todo respeto, que la mujer es una pasión útil.

- May interesante. Y sabes - empezó a tutearlo - la definición de la Nada?

- La nada es lo que queda cuando los poderosos se llevan lo que debía distribuirse entre todos.

- Fabuloso! - exclamo Némesis entusiasmada. Explícame lo que es la angustia.

- La angustia es lo que siente un hombre de setenta años en una luna de miel con una mujer de veinte-contestó prontamente Pedro.

En muchos casos el chiste filosófico brota sólamente sentido que de la vida tiene el autor, sin otro basamento:

"A la chica aquella le hice un poema porque el amor en la adolescencia produce versos, en la madurez dolores de cabeza y en la vejez ya no produce más que frustación. El amor es como los seguros de vida: que mientras mas años uno tiene más cuestan. De mis recuerdos saco en conclusión lo siguiente: uno nunca pretende ser lo que es sino aparentar lo que es..." (152)

Los caminos indicados son, pues, los recorridos por Alvaro de Villa. Celedonio González, al que se apostilla, inmediatamente, es la antítesis de todo lo anterior. En su novela, Los cuatro embajadores,7 trata de retratar el chiste negro, el cuajado de amargura. Ese que se encuentra, entre los trabajadores sometidos al cansancio físico y espiritual del bureo diario. Los Cuatro Embajadores relata la vida de un grupo de cubanos que trabajan en el hotel "The Four Ambassador," en Miami, en la Florida. 
Un chiste negro de Bum, un personaje que sirve de introducción al capítulo, da la tónica de los que se encuentran en la novela; se caracteriza por la carencia de risa. No mueve a ella. Esta carencia da el índice de lo que ha sido la vida fuera de la patria de un gran segmento de cubanos: han perdido la capacidad chistosa, esa que acompaña siempre al habitante de la Perla de las Antillas. El chiste de Bum es el siguiente: "Pobrecitos los pescaditos que no tienen sus bracitos..." (238)

Del mismo tenor son los otros chistes que encontramos. Uno de ellos se encuenran en: "LAS REGLAS DE URANIO, DE UN WAITER DE BANQUETES, ESTELAR"; 7, Si hay tiempo de sobra servir - lo que no sea líquido - por la izquierda. Si no lo hay, convertirse en ambidextro. 8. Servir los líquidos exactamente sobre el recipiente objeto del servicio, fijándose que esté bocarriba. (225)

$O$ en otro sitio de la novela:

- A dónde vas?

- A hacer pipi.

- Llevas con que?

- Por desgracia. (165)

En conclusión: las novelas citadas son un ejemplo de lo que es el chiste en el exilio cubano. Muestran que la forma de hacerlos lleva la impronta de la vida anímica y física del desterrado en lucha constante con el medio, muy diferente, en todo, al que existía en su patria, lucha que lo acibara o lo vuelve un filósofo de la existencia. Que por lo tanto, el chiste del exilio es diferente al que hacía el exiliado en Cuba, pues mientras el de alla era puro, con el sólo ánimo de lograr la risa de sus oyentes, el de aquí, o bien tiene un humor negro o bien está preñado de elementos filosóficos e irónicos.

\section{NOTAS}

1 Es que hay, en la esfera universal del chiste, uno que tiende a llevar, en lo risible, una carga de amargura.

2 (Miami: Editora Universal, 1972).

3 (Miami: Editora Universal, 1978).

4 De aquí en adelante, los números después de los chistes de Alvaro de Villa corresponden a las páginas de su novela, Los "pobresitos" pobres, (Miami: Ediciones Universal, 1973). 
5 Algunos (de ello) fueron publicados en unos artículos que vieron la luz en la Revista, "Carteles," de La Habana, la serie se titulaba: Memorias de Narciso Bello. Si se comparan estos artículos chistosos donde, machaco, se encuentran chistes repetidos más tarde, en Los "pobresitos" pobres, con ésta novela, se verá que en la misma adquieren otro tono: filosófico.

6 Se trata de un juego de palabras ("pun") entre "pis" - orinar en ingles - y "bis."

7 (Miami: Editora Universal, 1973). De ahora en adelante los números después de la citas que se hacen de Celedonio González corresponden a páginas de este libro.

University of North Carolina At Greensboro 